\title{
CAEP position statement on bystander cardiopulmonary resuscitation
}

\author{
Working group: Christian Vaillancourt, MD; Norman Epstein, MD; Sheldon Cheskes, MD; \\ Justin Maloney, MD; Ian G. Stiell, MD; James Christenson, MD; Andrew Affleck, MD; \\ Andrew H. Travers, MD; Martin H. Osmond, MD; Patrick Forgie, ACP; Jason Slenys, ACP
}

\section{EXECUTIVE SUMMARY}

Cardiovascular disease is the leading cause of death in North America. There are 53 to 59 out-of-hospital cardiac arrest (OOHCA) victims for which resuscitation is attempted per 100,000 of population, ${ }^{1,2}$ representing more than 20,000 cardiac arrests per year in Canada. Less than 2,000 (10\%) of these victims will survive, usually with a quality of life similar to that of the general population. ${ }^{3}$ OOHCA victims are three to four times more likely to survive when receiving bystander cardiopulmonary resuscitation $(\mathrm{CPR}),{ }^{4}$ but CPR rates rarely exceed $25 \%$ in Canada. ${ }^{1}$ Increasing our bystander CPR rate to $50 \%$, as it is the case in some communities, ${ }^{5,6}$ could result in an additional 2,000 lives saved each year in Canada. Unfortunately, recent strategies to improve bystander CPR rates have not been successful.

\section{CAEP POSITION}

CPR is a "Life Skill" acquired by too few Canadians. CAEP endorses all activities that will lead to an increase in bystander CPR rates for out-of-hospital cardiac arrest victims (with the exception of those victims having formally expressed the wish to not be resuscitated prior to the cardiac arrest event).

- Every Canadian should be trained in CPR.
- All Canadians should respond and provide chest compressions (with or without mouth-to-mouth ventilation) whether they are trained or not, when an adult, child or infant suddenly collapses. Trained rescuers are encouraged to provide mouth-to-mouth after the initiation of chest compressions, especially in the case of children, infants, newborns.

- Those with physical limitations precluding the performance of CPR should be trained to recognize the early signs of cardiac arrest, and immediately call for help.

- 9-1-1 ambulance dispatch-assisted CPR instructions are an effective method to increase bystander CPR All ambulance dispatch centers should provide dispatch assisted pre-arrival CPR instructions in all cases of cardiac arrest.

\section{INTRODUCTION}

Cardiovascular disease is the leading cause of death in North America. Sudden cardiac arrest occurs in the prehospital setting in more than $60 \%$ of all cases,, 78 and constitutes the first manifestation of cardiovascular disease for $50 \%$ of all victims. ${ }^{9}$ Approximately $50 \%$ of OOHCA events are witnessed by a bystander, and $30 \%$ to $40 \%$ of victims have an initial electrical rhythm amenable to defibrillation at the time of the arrest. ${ }^{1,2}$ Public access defibrillation programs have been shown

\footnotetext{
University of Ottawa (C.V., I.G.S.), Ottawa Hospital Research Institute, Ottawa, ON, Canada; University of Toronto (N.E.), Credit Valley Hospital, Mississauga, ON, Canada; Sunnybrook-Osler Center for Prehospital Care (S.C.), Toronto, ON, Canada; University of Ottawa (J.M., C.V.), Regional Paramedic Program for Eastern Ontario, Ottawa, ON, Canada; University of British Columbia (J.C.), Department of Emergency Medicine, Vancouver, BC, Canada; Thunder Bay Regional Health Sciences Center (A.A.), Thunder Bay, ON, Canada; Emergency Health Services (A.T.), Dartmouth, NS, Canada; University of Ottawa (M.H.O.), Children's Hospital of Eastern Ontario, Ottawa, ON, Canada; Advanced Care Paramedic (P.F., J.S), Peel Regional Paramedic Services, Peel, ON, Canada.
}

Corresponding author: Dr. Christian Vaillancourt, Ottawa Hospital, Civic Campus, Clinical Epidemiology Unit, F658, 1053 Carling Ave., Ottawa, ON, Canada K1Y 4E9; Telephone: (613) 798-5555 ext.17012; Fax: (613) 761-5351; E-mail: cvaillancourt@ohri.ca. 
to significantly improve the survival of victims suffering from cardiac arrest in public locations, ${ }^{10}$ but $85 \%$ of all OOHCA occur in residential dwellings, ${ }^{1}$ where early public defibrillation programs have not been successful. ${ }^{11}$ Overall survival to hospital discharge for OOHCA victims where resuscitation efforts were attempted rarely exceeds $10 \% .^{1,2}$

\section{BACKGROUND AND PROBLEM DEFINITION}

Bystander CPR rates as high as 50\% and survival rates to hospital discharge as high as $15 \%$ have been reported in some communities. ${ }^{5,6}$ In Canada, there are several ongoing campaigns and attempts to improve community bystander CPR and survival rates. Organizations responsible for CPR training campaigns in the community include (and are not limited to) the Heart and Stroke Foundation, the St. John Ambulance, the Red Cross, the Canadian Ski Patrol, the ACT Foundation, and several other emergency medical services, city wide, and for-profit initiatives. The Heart and Stroke Foundation of Canada estimates that $60 \%$ of all Canadians have been trained at least once in CPR. Unfortunately, CPR skills are often not practiced and kept up-to-date, leading to hesitation and inaction when faced with a cardiac arrest situation.

\section{REVIEW OF CURRENT POLICY OPTIONS}

Popular strategies adopted to promote bystander CPR rates usually involve: trying to teach CPR to as many people as possible in the community, targeting CPR training for those most at risk to encounter a cardiac arrest victim, and promoting 9-1-1 dispatch-assisted CPR instructions. Individually, these strategies can only offer limited results, and should be adopted concurrently. Mass CPR training events can successfully teach CPR to a large number of people at a time, ${ }^{12-14}$ but have a tendency to reach younger participants less likely to live with a potential cardiac arrest victim..$^{15,16}$ Family members of patients with known cardiovascular disease can learn and benefit from CPR training, ${ }^{17,18}$ but only $50 \%$ of OOHCA victims have known cardiovascular disease before the event. ${ }^{9}$ While dispatch-assisted CPR instructions have been shown to improve bystander CPR rates, ${ }^{19}$ better survival outcomes have been observed in groups where $\mathrm{CPR}$ instructions were provided to previously trained providers. ${ }^{20}$
The American Heart Association and the Heart and Stroke Foundation of Canada have published updated resuscitation guidelines in 2010, including recommendations aiming to simplify and facilitate CPR training in the community. ${ }^{21,22}$ Those include: chest compressiononly CPR (in adults) for untrained responders and for those reluctant to provide ventilations, changing the $\mathrm{CPR}$ sequence to $\mathrm{C}-\mathrm{A}-\mathrm{B}$ (instead of A-B-C) where chest compressions are initiated before the airway and breathing are assessed, promoting self-teaching, video-based CPR training, and recommending that CPR training sessions be simple, consistent, objective-based, contextual, and include practice "until mastery". It is now the responsibility of Government and agencies at the national, provincial, and community level to implement strategies that will result in knowledge translation of CPR skills in the community, leading to increased bystander CPR for OOHCA victims and subsequent increase in successful resuscitation and survival.

\section{RECOMMENDATIONS}

It is not acceptable that vast numbers of witnessed cardiac arrest victims do not receive bystander CPR. Most often, those who undertake CPR training are required to do so as a pre-requisite for work. Agencies like the Heart and Stroke Foundation and the St. John Ambulance have promoted CPR education for years Their efforts have maintained a reasonable number of CPR trained citizens, but these have not resulted in bystander CPR delivery in the majority of cardiac arrest victims. This limitation is likely to persist as long as the education is pursued on a voluntary basis. There needs to be strong inducements and a systematic approach to ensure more people in the community are prepared and ready to perform this life saving skill.

CAEP proposes a multi-pronged approach to advance CPR education in the larger community. This includes government initiatives, and working in coalition with various other organizations in the health care field.

\section{Government initiatives:}

\section{1) Compulsory CPR education should be imple- mented in high school.}

CPR education should be a pre-requisite for a graduating student to earn a high school diploma. Currently, CPR education in schools is optional and 
depends on the emphasis placed by each respective school board. In Ontario, British Columbia, and Alberta, CPR education is introduced in Grade 9 or 10.

2) Tax exemptions should be enacted to allay costs to companies that provide CPR education and to individuals who take CPR education.

Many people, including low income senior citizens, choose not to enroll in a CPR course due to the expense. A $100 \%$ tax rebate would clearly offset this obstacle. More importantly, it would provide a compelling tax incentive to a large company to sponsor CPR education for its employees which, in turn, would ensure a safer workplace.

\section{Non-government initiative:}

CAEP should build a coalition with like-minded stakeholders to spearhead a national campaign to advance the cause of bystander CPR. In addition to the Heart and Stroke Foundation of Canada and the St. John Ambulance, other stakeholders could include the ACT Foundation, the Canadian Medical Association, the Canadian College of Family Physicians, the Canadian Cardiovascular Congress, the Canadian Nursing Association, and the Paramedic Association of Canada.

An initial campaign could entail printing wallet size cards that succinctly explain the importance of CPR together with a computer link and telephone number to find out when and where courses are held. These cards could be given to next of kin of patients in emergency departments. Family physicians doing a complete physical exam or periodic assessments should give out the card to all their patients, considering that as many as $50 \%$ have undetected heart disease. However, family doctors should not just be merely giving them out in their waiting rooms but affirm its significance in direct communication. Needless to say, cardiologists should be promoting it in their offices.

Such a campaign should be strongly promoted in every conceivable health venue, including senior citizens and retirement homes, notwithstanding the limitations some elderly may have in doing CPR. Targeting senior citizens is of particular importance since they represent the population most at risk to witness a cardiac arrest. This awareness campaign should include as many municipal, provincial and federal government interactions as possible.

\section{CONCLUSION}

It must become a moral obligation and a social expectation that bystanders will perform CPR when they witness a cardiac arrest. The general population must come to understand that cardiac resuscitation is much more likely to be successful when CPR is started promptly, and the victims of cardiac arrest will almost certainly die if lay witnesses do not intervene. There must be widespread recognition that CPR is a simple but vital life skill everyone should learn and then put into practice in emergency situations.

\section{CAEP POSITION STATEMENT ON BYSTANDER CARDIOPULMONARY RESUSCITATION}

Declared potential or perceived conflict of interest by working group authors:

Dr. Christian Vaillancourt:

Dr. Vaillancourt received funding from the Canadian Institutes of Health Research, The Heart and Stroke Foundation of Ontario, and The Heart and Stroke Foundation of Canada to study community bystander CPR and 9-1-1 dispatcher-assisted CPR instructions. He holds a research chair in emergency cardiac arrest resuscitation, University of Ottawa, and is an investigator for the Ottawa site of the Resuscitation Outcomes Consortium.

Dr. Norman Epstein:

No conflict

Dr. Sheldon Cheskes:

Dr. Cheskes is a co-Principal Investigator for the Toronto site of the Resuscitation Outcomes Consortium.

Dr. Justin Maloney:

No conflict

Dr. Ian G. Stiell:

Dr. Stiell is the Principal Investigator for the Ottawa site of the Resuscitation Outcomes Consortium.

\section{Dr. James Christenson:}

Dr. Christenson is a volunteer expert for the Heart and Stroke Foundation of BC and Yukon regarding CPR and AED programs. He is also the Principal Investigator for the British Columbia site of the Resuscitation Outcomes Consortium.

Dr. Andrew Affleck:

Dr. Andrew Affleck is the Base Hospital Medical Director for the Northwest Region of Ontario, and is involved with the Resuscitation Outcome Consortium research group in investigating the efficacy of various components of CPR in the prehospital care. 


\section{Dr. Andrew H. Travers:}

Dr. Travers is the Basic Life Support Heart and Stroke Foundation of Canada (HSFC) Liaison to the Emergency Cardiac Care Committee for the American Heart Association (AHA), and is an International Liaison Committee on Resuscitation (ILCOR) delegate for the HSFC.

Dr. Martin H. Osmond:

No conflict

\author{
Patrick Forgie: \\ No conflict \\ Jason Slenys: \\ No conflict
}

\section{REFERENCES}

Please see the references list at the end of the French version.

\title{
Déclaration de I'ACMU sur la réanimation cardio-respiratoire effectuée par un passant
}

\author{
Groupe de travail : Christian Vaillancourt, MD; Norman Epstein, MD; Sheldon Cheskes, MD; \\ Justin Maloney, MD; Ian G. Stiell, MD; James Christenson, MD; Andrew Affleck, MD; \\ Andrew H. Travers, MD; Martin H. Osmond, MD; Patrick Forgie, ACP; Jason Slenys, ACP
}

\section{RÉSUMÉ}

La maladie cardiovasculaire est la principale cause de décès en Amérique du Nord. On compte entre 53 et 59 victimes d'arrêt cardiaque en milieu non hospitalier (OOHCA) pour qui la réanimation est tentée par 100000 de population, ${ }^{1,2}$ ce qui représente plus de 20000 arrêts cardiaques par année au Canada. Moins de 2000 $(10 \%)$ de ces victimes survivront, généralement avec une qualité de vie similaire à celle de la population générale. ${ }^{3}$ Les victimes d'OOHCA ont entre trois et quatre fois plus de chances de survivre quand elles reçoivent la réanimation cardio-respiratoire (RCR) effectuée par un passant, ${ }^{4}$ mais les taux de RCR dépassent rarement $25 \%$ au Canada. ${ }^{1}$ Atteindre un taux de RCR effectuée par un passant de 50\%, comme c'est déjà le cas dans certaines communautés,, 5 pourrait permettre de sauver 2000 vies de plus chaque année au Canada. Malheureusement, les stratégies récentes pour améliorer les taux de RCR effectuée par un passant sont restées sans succès.

\section{POSITION DE L'ACMU}

La RCR est une connaissance de base acquise par trop peu de Canadiens. L'ACMU appuie toutes les activités qui entraîneront une augmentation des taux de RCR effectuée par un passant pour les victimes d'arrêt cardiaque en milieu non hospitalier (avec l'exception des victimes ayant formellement exprimé, avant l'arrêt cardiaque, le désir de ne pas être réanimées).

Université d'Ottawa (C.V., I.G.S.), Institut de recherche de I'hôpital d'Ottawa, Ottawa, ON, Canada; Université de Toronto (N.E.), Credit Valley Hospital, Mississauga, ON, Canada; Sunnybrook-Osler Center for Prehospital Care (S.C.), Toronto, ON, Canada; Université d'Ottawa (J.M., C.V.), Regional Paramedic Program for Eastern Ontario, Ottawa, ON, Canada; University of British Columbia (J.C.), Department of Emergency Medicine, Vancouver, BC, Canada; Thunder Bay Regional Health Sciences Center (A.A.), Thunder Bay, ON, Canada; Emergency Health Services (A.T.), Dartmouth, NS, Canada; Université d'Ottawa (M.H.O.), Children's Hospital of Eastern Ontario, Ottawa, ON, Canada, Advanced Care Paramedic (P.F., J.S), Peel Regional Paramedic Services, Peel, ON, Canada.

Auteur-ressource : Dr Christian Vaillancourt, Hôpital d'Ottawa, campus Civic, unité d'épidémiologie clinique, F658, 1053 Carling Ave., Ottawa, ON, Canada K1Y 4E9; Téléphone : 613-798-5555, poste 17012; Fax : 613-761-5351; Courriel : cvaillancourt@ohri.ca. 